\title{
A família frente ao processo de tratamento e reinternação do portador de esquizofrenia
}

\author{
Andressa Behenck ${ }^{1}$ \\ Alessandra Dartora da Silva ${ }^{2}$ \\ Dorisdaia Carvalho de Humerez ${ }^{3}$ \\ Joel Rolim Mancia
}

Recebido em: 17/04/2011

Aceito em: 23/11/2011

A esquizofrenia é uma doença complexa pois, além de ser orgânica, sofre interferências ambientais que potencializam o indivíduo predisposto a vir a desenvolvê-la. O objetivo deste estudo foi conhecer a compreensão das famílias sobre o processo de tratamento ea reinternação do familiar com esquizofrenia. É um estudo exploratório-descritivo com abordagem qualitativa. Os sujeitos foram oito familiares de pacientes do sexo masculino, em internação psiquiátrica pela segunda vez, ou mais, que aceitaram participar da pesquisa. Foi usada a entrevista semiestruturada e, a seguir, a análise do conteúdo que permitiu identificar as categorias: Falhas do serviço sob a perspectiva familiar; Compreensão da família em relação à esquizofrenia; Não adesão ao tratamento; Comorbidade: uso de drogas associado à esquizofrenia; e A doença avançada. Conclui-se que as famílias têm necessidade de compreender a esquizofrenia e as formas de tratamento e o enfermeiro está habilitado para orientá-las bem como no controle da doença, remissão dos sintomas e agravamento.

Descritores: Esquizofrenia, Transtorno Mental, Enfermagem.

\section{The family in the process of treatment and hospital readmission of patients with schizophrenia}

Schizophrenia is a complex disease, because besides being organic, suffers interference that empowers the individual to come predisposed to develop it. The aim of this study was the understanding families about the process of treatment and hospital readmission of the family member with schizophrenia. It is an exploratory descriptive study with qualitative approach. The subjects were eight relatives of male patients in psychiatric hospital for the second time or more, who agreed to participate. It was used semi-structured interview and then content analysis that allowed to identify the following categories: Service failures in the family perspective, understanding the family in relation to schizophrenia, not adherence to treatment, co-morbidity: drug use associated with schizophrenia, and advanced disease. It is concluded that families need to understand schizophrenia and forms of treatment and the nurse is able to guide the families and control the disease, remission of symptoms and aggravation.

Descriptors: Schizophrenia, Mental Disorder, Nursing.

\section{La familia en el proceso de tratamiento y la readmisión de los pacientes con esquizofrenia}

La esquizofrenia es una enfermedad compleja, además de ser orgánica, sufre interferencias que permiten a las personas a venir con predisposición a desarrollarla. El objetivo de este estudio fue la comprensión de las familias en el proceso de tratamiento y la readmisión de la familia con esquizofrenia. Se trata de un estudio exploratorio descriptivo con enfoque cualitativo. Los sujetos fueron ocho los familiares de pacientes del sexo masculino en un hospital psiquiátrico por segunda vez o más, que aceptaron participar de la investigación. Se utilizó la entrevista semiestructurada y el análisis de contenido identificó las categorías de fallas en el servicio en la perspectiva de la familia, la comprensión de la familia en relación con la esquizofrenia; la no adherencia al tratamiento, co-morbilidad del consumo de drogas asociado con la esquizofrenia y la enfermedad avanzada. Se concluye que las familias necesitan entender la esquizofrenia y las formas de tratamiento y la enfermera es capaz de guiar a ellos, así como control de la enfermedad y remisión de los síntomas y molestias.

Descriptores: Esquizofrenia, Trastorno Mental, Enfermería.

\section{INTRODUÇÃO}

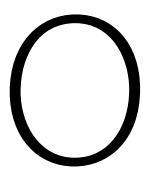
movimento de Reforma Psiquiátrica no fim da década de 1970 estabeleceu como foco principal a desinstitucionalização do portador de sofrimento psíquico, com intenção de reintegrá-lo à família e à sociedade. Esse processo de desospitalização acarretou à família o confronto com a realidade do convívio e o cuidado do sujeito que sofre o estigma da loucura, sujeito este que até então encontrava-se na maioria das vezes, confinado e excluído pela hospitalização.
Entre 1960 e 1970, a política de saúde mental do Brasil usava o modelo hospitalocêntrico, com significativo aumento de leitos nos hospitais psiquiátricos ${ }^{(1)}$. Em 1987, ocorreu a I Conferência Nacional de Saúde Mental no Brasil, ano marcado pelo surgimento do primeiro serviço substitutivo ao hospital psiquiátrico, o Centro de Atenção Psicossocial (CAPS), na cidade de São Paulo. Foi essa intervenção, com repercussão nacional, que demonstrou a possibilidade da construção efetiva de serviços que podem substituir a assistência hospitalocêntrica ${ }^{(2)}$.

1 Enfermeira. Graduada pelo Centro Universitário Metodista do IPA

2 Enfermeira. Mestre em Educação. Professora do Centro Universitário Metodista do IPA.

3 Enfermeira. Doutora em Enfermagem. Professora Adjunto da Universidade Federal de São Paulo.

4 Enfermeiro. Doutor em Enfermagem. Professor do Centro Universitário Metodista do IPA.

5 Enfermeira. Doutora em Enfermagem. Professora Associada da Universidade Federal de Santa Catarina. Pesquisadora do CNPq. 
A partir desse fato, o número de leitos psiquiátricos vem diminuindo gradualmente, sendo em 1984, 105.765 leitos e caindo para 85.087 em 1991, redução de $20 \%$ de leitos para internação(1).

Dentre os transtornos mentais que tinham como possibilidade de tratamento a internação, a Esquizofrenia ocupa destaque no ranking dos mais conhecidos e discutidos pela sociedade.

A incidência de Esquizofrenia no Brasil é similar à de outros países, atingindo quatro em cada 10 mil adultos ${ }^{(3)}$.

De acordo com Associação de Psiquiatria Americana(4), a Esquizofrenia atinge $1 \%$ da população adulta em ambos os sexos. e 25 anos de idade, e a evolução do quadro no sexo masculino geralmente apresenta maior comprometimento dos sintomas negativos. Uma das características dos homens esquizofrênicos é não conseguir estabelecer relação fixa e duradoura, o que os faz permanecer solteiros, além de apresentar danos na interação social e resistência a adesão do tratamento. Consequentemente, sofre um maior número de internações do que o sexo feminino. Nas mulheres, a Esquizofrenia manifesta-se e desenvolve-se de forma mais positiva. Em geral elas são mais adequadas socialmente, são casadas ou separadas e ainda cuidam de seus filhos e, além disso, aderem ao tratamento mais facilmente $e^{(5)}$. As características dos portadores de esquizofrenia são semelhantes a algumas características de masculinidades e feminilidades presentes nas relações de gênero, o que pode contribuir para um diagnóstico tardio e dificuldades de adesão ao tratamento, principalmente no que se refere aos comportamentos masculinos.

A sobrecarga imposta à família na

\section{"A esquizofrenia acomete mais precocemente homens, entre 15 e 25 anos, e com a evolução da doença, geralmente apresentam sintomas negativos"} O surgimento da doença acontece mais precocemente, entre 15

tipo de pesquisa possibilita descrever e compreender o mundo de representações que esse transtorno mental significa.

Participaram do estudo 8 familiares de pacientes masculinos portadores de esquizofrenia, que estavam em situação de internação pela segunda vez (ou mais) no momento da pesquisa. A delimitação da amostra deu-se pela saturação dos dados. O estudo foi realizado no Hospital Psiquiátrico São Pedro(9), na unidade Mário Martins Masculina, na cidade de Porto Alegre/RS. Foram considerados familiares aqueles responsáveis pelo cuidado do paciente, independentemente das relações familiares e dos laços consanguíneos.

A coleta de dados foi realizada através de entrevista semiestruturada. As questões da entrevista foram adequadas à linguagem do grupo em foco ${ }^{(10)}$. Abordou-se o funcionamento do sistema familiar do paciente portador de esquizofrenia, opiniões, pensamentos e sentimentos do(s) familiar(es) sobre o tratamento e o processo de reinternação de seu ente em distúrbio psíquico e, ainda, as perspectivas da recuperação. As entrevistas foram gravadas, com o consentimento dos participantes.

A análise dos dados foi realizada conforme o método de análise de conteúdo ${ }^{(8)}$. A maioria dos entrevistados está compreendida entre a faixa etária de 40 a 50 anos. Com base nas entrevistas fornecidas pelos familiares, foi possível identificar que grande parte dos pacientes foram diagnosticados esquizofrênicos tardiamente, com cerca de 25 anos e após já terem apresentado o primeiro episódio de surto psicótico. Todos os pacientes tinham registrado, em prontuário, mais de cinco internações psiquiátricas no momento da pesquisa.

Após a leitura das entrevistas, realizouconvivência com o esquizofrênico é sobretudo financeira pois, muitas vezes, antes de adoecer, o sujeito trabalhava e contribuía com o orçamento doméstico. Porém, com o surgimento da doença, torna-se significativa a probabilidade de abandono ou demissão do emprego. São descritas também a sobrecarga nas rotinas familiares, bem como as dificuldades emocionais e físicas enfrentadas pelos mesmos ${ }^{(6)}$.

O processo de desinstitucionalização do doente mental proposto pela reforma psiquiátrica vem acontecendo lentamente. Entretanto, essa proposta espera que os portadores de transtornos mentais, incluindo pacientes esquizofrênicos, venham conquistar seu espaço na sociedade, seguindo o tratamento sugerido, seja com acompanhamento ambulatorial, em CAPS ou em hospitais dia.

O objetivo deste estudo é conhecer a compreensão das famílias sobre o tratamento e o processo de reinternação de um familiar portador de esquizofrenia.

\section{PROCEDIMENTOS METODOLÓGICOS}

É uma pesquisa exploratório-descritiva de abordagem qualitativa ${ }^{(7,8)}$. Na intenção de explorar o universo dos portadores de esquizofrenia e dos que com eles convivem, esse -se um mapeamento das respostas, emergindo cinco categorias: Falhas do serviço sob a perspectiva familiar; Compreensão da família em relação à esquizofrenia; Não adesão ao tratamento; Agressão e reações do surto; Co-morbidade: uso de drogas associado à esquizofrenia e doença avançada.

O estudo atende a resolução 196/96 sobre pesquisas envolvendo seres humanos, incluindo o indivíduo e a coletividade. Também obteve-se aprovação do comitê de ética em pesquisa do Instituto Metodista do Sul, IPA e do comitê do Hospital Psiquiátrico São Pedro. Somente mediante a aprovação de ambos os comitês, foi dado início à pesquisa.

Todos os participantes se dispuseram a colaborar com o estudo e assinaram o Termo de Consentimento Livre e Esclarecido. Os informantes tiveram liberdade de interromper a entrevista ou de negar-se a responder algumas questões, discorrendo sobre os tópicos livremente.

\section{RESULTADO E DISCUSSÃO}

\section{Falhas do Serviço sob a Perspectiva Familiar}

A proposta de desinstitucionalização do portador de sofrimento psíquico não tem sido tarefa fácil para as famílias. Elas enfrentam dificuldades para manter o familiar no convívio 
social, principalmente pela falta de infraestrutura comunitária, como serviços substitutivos de saúde mental eficientes e formas de lidar com o portador de transtorno mental.

Os depoimentos a seguir demonstram algumas falhas do serviço e dificuldades enfrentadas pelos familiares na busca de um tratamento eficaz.

"[...] Em função dos problemas que ele teve de agressão com o CAPS, a psiquiatra de lá não quer mais saber do P., não me dá receita pra comprar medicação pra ele [...] quando eu vou ao postinho, eles me encaminham pro CAPS, e o CAPS não quer mais porque diz que não está em contato todo o dia com o $P$., não atendem ele, eu fico com as mãos amarradas, mesmo que eu queira eu não consigo [...] [...] O CAPS não quer mais vincular o $P$. Daí ele não consulta e eu não consigo pegar receita. Será que eu vou ter que me fazer de louca pra conseguir receita pro P.? [...] Nesses hospitais ninguém fala comigo direito que nem a senhora está falando. Só me dizem que ele tem esquizofrenia, mas não me explicam nada direito [...] [...] eu só sei que ele tem isso, e que ele quebra tudo em casa e quer sempre estar sozinho. Eu pergunto o que ele tem pro doutor. Ele diz mas eu não entendo mesmo assim, u fico com vergonha de ficar perguntando sempre, né?!

O CAPS é o atendimento extra-hospitalar de referência da maior parte das pessoas que possuem um familiar doente mental. Todos os familiares, quando questionados sobre esse centro, responderam que já procuraram o serviço pelo menos uma vez, porém muitos deles apresentaram incredibilidade na rede que se propõe à substituição da internação hospitalar.

As falas registram a oposição dos familiares ao serviço e ao despreparo daquele que deveria ser a âncora da rede substitutiva de saúde mental e que fundamentalmente deveria oferecer um trabalho essencialmente baseado na integralidade e intersetorialidade.

"[...] É assim, ó: eu também tô no CAPS, tô sem psiquiatra, faz 10 meses que eu não consulto. Não tem psiquiatra lá, eles ficam enrolando a gente só com psicólogo, fica aquele grupinho só falando coisa ruim, cada um fala o seu problema, eu saio pior dali de dentro, o problema é maior. E o M. não tem paciência de ficar nesses grupos. O que acontece, se ele não vai ao grupo, eles cortam o M. do CAPS e mandam pegar a receita no posto... [...] eu acho que o CAPS não é tratamento para o paciente, não considero um bom tratamento, porque lá eles ficam no meio de viciados, no meio de pessoas que têm mais problema que eles, eles se misturam e ficam trocando ideias. Para os meus filhos foi pior o CAPS..."

No depoimento de um dos familiares participantes da pesquisa, foi possível perceber a concepção completamente hospitalocêntrica do próprio familiar em relação ao tratamento de seu ente.

"[...] o hospital influi muito no tratamento do paciente. Sem hospital não tem tratamento pra doente mental, em casa não tem como um familiar tratar de um doente mental [...] [...] é a falta de um hospital em casa que pudesse manter ele preso, porque o dia que ele sai do hospital ele começa a se governar sozinho, e ele não tem condições de ter essa autonomia de maneira nenhuma..."

Se nesse novo contexto da atenção à saúde mental, a família é considerada essencial para o tratamento, também é inegável a sobrecarga nela imposta ao ter que assumir uma função ativa no tratamento de seu familiar em sofrimento psíquico. Além disso, a rede de serviços substitutivos e a equipe que nela se insere com profissionais da saúde mental precisa compreender as famílias como usuárias em potencial. Para isso, é imprescindível um serviço que apoie a família, esclareça dúvidas e oriente-as em suas dificuldades, de modo que ambos, o paciente e a família, possam conduzir suas vidas sem comprometimento da saúde mental ${ }^{(11)}$.

\section{Compreensão da Família em Relação à Esquizofrenia}

A esquizofrenia é doença crônica que pode ser tratada e controlada com diversas formas de tratamento, incluindo terapia medicamentosa associada a psicoterapia individual, familiar e em grupo, além de programas de psicoeducação e reabilitação social. Observa-se que os mais envolvidos com os efeitos da doença, paciente e família, são os menos informados e orientados sobre ela.

"[...] Eu acho que a esquizofrenia é a doença mais horrível do mundo, é pior que a AIDS, eu acho...

[...] ele resolve parar de tomar a medicação porque acha que tá curado e volta tudo, eu penso que nunca ninguém explicou pra ele o que ele tem, ele não sabe que tem que tomar esses remédio sempre, eu falo, mas ele não acredita em mim. Acho que um doutor e a senhora podiam falar isso pra ele..."

A maneira como a família interpreta o transtorno mental de um de seus membros influencia as práticas de cuidado por ela adotadas, e a reabilitação satisfatória do paciente depende da relação estabelecida entre o cuidador e aquele que é cuidado ${ }^{(12)}$.

A convivência com a esquizofrenia pouco compreendida leva frequentemente os familiares a tomarem decisões drásticas ou a planejar ações que possam desvencilhar os laços com o doente.

"[...] eu saí de casa, eu não quero mais voltar a conviver com isso, eu já sofri demais [...] eu sou traumatizada com o P., com o que ele me fez sofrer...

[...] já pensei em matar o meu filho e depois me matar..."

Visto que, quando a família descobre qual o diagnóstico de seu ente, falta-lhe saber seu significado para ter noção do que realmente está ocorrendo e para estabelecer quais serão as estratégias adotadas para o enfrentamento da doença. As famílias não estão preparadas para esses eventos, e muito menos Ihes foi orientado sobre o prognóstico da doença.

Portanto, cabe aos profissionais de saúde mental, em especial à Enfermagem, informar e orientar, detalhadamente, os familiares e os pacientes sobre a doença e suas possíveis manifestações e, sobre a importância da adesão e perseverança no tratamento psicodinâmico contra o agravamento dos sintomas na esquizofrenia, podendo ser decisivas no fator da cronicidade da doença. 


\section{Não Adesão ao Tratamento}

No transcorrer da esquizofrenia, os pacientes e seus familiares vivenciam períodos de controle e diminuição dos sintomas, alternados a momentos de crises, recaída psiquiátrica e, na maior parte das vezes, reinternação hospitalar dos doentes.

No tratamento de transtornos mentais, a não adesão à medicação é observada em $50 \%$ dos casos, sendo responsável por diversos prejuízos, além de constituir a principal causa de agravamento da doença e reinternações ${ }^{(13)}$. Percebemos a resistência dos pacientes ao tratamento nas declarações a seguir:

"[...] aí eu tento dar a medicação pra ver se ele melhora e ele não aceita, aí começa tudo de novo, eu tenho que levar ele pro hospital, é muito difícil..."

"[...] ele não me respeita, não quer tomar as medicação, aí ele entra em crise e vem o surto..."

"[...] ele não aceita tomar a medicação, ele me disse que um dia vai me meter um processo, que a gente tá dando o remédio errado, que ele não é doente mental [...] Aí eu dou a medicação pra ele e ele faz que toma e bota embaixo da língua..."

Evidencia-se a importância da aplicação do uso de terapias, além da medicamentosa, principalmente atividades que propõem um ocuparse do tempo, do ócio, assim deslocando o foco centralizado na doença e direcionando-o ao usuário. Com o olhar profissional voltado ao portador de doença mental, tornam-se mais fáceis a percepção, a compreensão das necessidades do doente, bem como a eficácia da assistência em saúde mental.

\section{Agressão e Reações do Surto}

A não adesão ao tratamento acarreta inúmeras consequências ao portador de doença metal, dentre elas o desencadeamento de um novo surto. A heteroagressão física e psicológica e o comportamento inadequado/desorganizado são as manifestações mais frequentes em um surto. Há um risco sete vezes maior de pacientes portadores de esquizofrenia cometerem atos violentos se comparados a outros transtornos mentais ${ }^{(14)}$.

"[...] ele já quebrou prato na minha cabeça, já correu com faca atrás de mim [...] [...] que é quando ele fica ruim, fica irritado quer se botar na gente, isso que é o pior, é a brabeza dele..."

"[...] ele quebrou tudo lá em casa, destruiu o quarto dele, o irmão dele tentou segurar ele, mas acabou apanhando junto, ele tava fora de si..." "[...] ele grita, não respeita ninguém. Se eu falo, aí ele ainda vem pra cima de mim, mesmo não falando nada, ele grita igual, mas se ele tá sem a medicação. Isso que eu quero deixar claro." tentou se jogar na frente do carro..."

Também foi evidenciado um caso de autoagressão e tentativa de suicídio:

"[...] agora, na penúltima vez, ele passou a faca no braço; outra vez foi um caco de vidro na perna, ele levou 13 pontos. Ele já tentou se jogar na frente do carro..."

A pessoa com esquizofrenia experimenta a realidade de forma diferente, e tal vivência invariavelmente gera conflitos nos relacionamentos pessoais com formas inadequadas de agir, hostilidade e isolacionismo.

\section{Co-morbidade: Uso de Drogas Associado à Esquizofrenia}

Os efeitos causados pelo uso de substâncias psicoativas, tais como diminuição da ansiedade, euforia e outras sensações percebidas como prazerosas pelo usuário tendem a ser fortes reforçadores do uso, especialmente nos transtornos psiquiátricos. Os pacientes com transtorno mental, devido ao sofrimento psíquico, estão mais vulneráveis ao consumo de drogas ${ }^{(14)}$.

A seguir, algumas declarações demonstram a co-morbidade do consumo de drogas associado à doença mental.

"[...] Aí ele não toma mais a medicação e vai pra droga, aí vem o surto, aí ele usa crack, maconha, some coisa dentro de casa..." "[...] Ele não se sente doente, ele acha que ele tem condições na vida social de beber, fumar [...] [...] Aí não adianta dizer pra ele não tomar álcool com a medicação, que é o que ele faz né?! [...] Ele vende o rádio e o que tiver pra poder arrumar dinheiro pra sair pra beber [...] Todas as vezes que ele bebia, no caso, ele não queria tomar medicação, né?! Aí ele chegava em casa e ia quebrando tudo, queria se botar em mim..."

Para o tratamento extra-hospitalar da dependência química, há os Centros de Atenção Psicossociais - Álcool e Drogas (CAPSad). Estes são considerados a principal estratégia de terapêutica (não hospitalocêntrica) contra o abuso de substâncias e têm por objetivo a reabilitação psicossocial de usuários de álcool e outras drogas, desenvolvendo ações intersetoriais efetivas para que esses pacientes venham a assumir sua condição de sujeito social ${ }^{(15)}$.

Os serviços disponibilizados para os pacientes com diagnóstico de esquizofrenia e que apresentam a co-morbidade da dependência química têm atendimento segmentado em rede de apoio que não oferece co-relação entre um tratamento e outro, isto é, a assistência ao portador de transtorno mental é prestada em um determinado momento, enquanto a abordagem ao consumo de drogas é realizada em outro serviço de saúde, dificultando o acesso e, consequentemente, a adesão ao tratamento.

Com isso, a atenção em saúde se contrapõe ao princípio da integralidade na assistência em saúde, preconizada pelas diretrizes do Sistema Único de Saúde ${ }^{(16)}$.

Fica evidente a necessidade de maior aprofundamento entre a relação da doença mental e o abuso de substâncias psicoativas, no sentido de planejar ações de atenção mais adequadas às necessidades dos usuários, facilitando a adesão aos programas de prevenção e tratamento.

\section{A Doença Avançada}

O fato de a esquizofrenia progredir em seu curso e tornar-se crônica foi um dos fatores apontados pelos familiares como agravante às reinternações.

"[...] daí parece que com o tempo fica cada vez pior, mesmo que ele esteja tomando os remédios. Tem uns remédios que ele já tomou que não fazem mais efeito [...]" (E4)

"[...] a mente se acomoda na doença e, com o tratamento, a pessoa volta um pouco a si e, com o tempo, a mente volta 
àquele estado novamente. É um vício, a mente vicia na doença e vai piorando ao longo do tempo [...]" (E7)

A detecção precoce da esquizofrenia, já na adolescência, pode contribuir para a redução dos quadros crônicos da doença ${ }^{(14)}$.

Medidas educacionais na comunidade em geral e a atenção dos profissionais que lidam com adolescentes poderá colaborar como alerta sobre diferentes manifestações de comportamento, devendo encaminhá-los à avaliação e a acompanhamento especializados.

\section{CONSIDERAÇÕES FINAIS}

Foi possível perceber a dificuldade das famílias em lidar com este transtorno mental, além de constatarmos falhas no serviço de atenção à saúde mental; incompreensão dos familiares e pacientes em relação à doença; e consumo abusivo de substâncias psicoativas por parte do portador de esquizofrenia.

Verificamosqueexistegrandeinfluência dessesfatoresna adesão ao tratamento, visto que a maioria dos pacientes esquizofrênicos não adere a nenhuma forma de terapêutica. Por essas razões, evidencia-se a necessidade de orientação aos pacientes e familiares quanto à importância do tratamento para a esquizofrenia, uma vez que aumentam as chances de se obter resultados positivos com o cumprimento das terapias psicodinâmicas.

Em relação às dificuldades de relacionamento, observa-se que a desarmonia familiar e agressões contribuem para o agravamento da doença; que para o familiar responsável pelo doente há muitas sobrecargas; que faltam orientações e apoio para os cuidadores; e que é fundamental a participação da família para o sucesso do tratamento do doente. Sabemos que a colaboração da família no cuidado com o paciente esquizofrênico é primordial. No entanto, observamos que muitas famílias não convivem bem com seu familiar portador de esquizofrenia, acarretando dificuldade do mesmo na realização efetiva do tratamento correto, e contribuindo para o processo de cronicidade da doença.

Portanto, é de extrema importância que as equipes e serviços de saúde mental ofereçam atenção em saúde, prestando assistência baseada nas necessidades dos pacientes e seus familiares, pois estes últimos exercem a função de cuidadores e ainda são responsáveis pela condução da vida de seus entes acometidos por uma doença que necessita, infinitamente, ser controlada.

A assistência de saúde mental aos esquizofrênicos deve atender ao princípio da integralidade, visto que o curso da doença é diferente em cada indivíduo. Os serviços devem ser integrados e articulados entre eles, além de trabalhar intersetorialmente, facilitando o acesso para os portadores de transtornos mental e seus familiares.

Sendo assim, ressaltando todo o conhecimento adquirido durante a construção deste trabalho, salientamos a importância da Enfermagem na assistência ao portador de esquizofrenia e sua família, uma vez que o enfermeiro psiquiátrico tem embasamento científico para informar e orientar os pacientes e familiares sobre a doença e seu curso, ampliando-lhes a visão para novas estratégias de tratamentos, e articulando os diversos serviços de saúde para que pacientes e família alcancem sua plena saúde mental ${ }^{(17,18)}$.

\section{Referências}

1. Alves DSN. Elementos para uma análise da assistência em saúde mental no

Brasil. J Bras Psiquiatr. 1992;41:423-6.

2. Ministério da Saúde (BR). Reforma psiquiátrica e política de saúde mental no

Brasil. Brasília: Ministério da Saúde; 2005. p. 6-9.

3. Mari JJ, Leitão JR. A epidemiologia da esquizofrenia. Rev Bras Psiquiatr.

2000;22:15-6.

4. American Psychiatric Association. Manual diagnóstico e estatístico de

transtornos mentais (DSM-IV). Porto Alegre: Artmed; 2002.

5. Chaves AC. Diferenças entre os sexos na esquizofrenia. Rev Bras Psiquiatr.

2000;22(1):21-2.

6. Koga M, Furegato RA. Convivência com a pessoa esquizofrênica: sobrecarga

familiar [Internet]. [citado em 2009 Out 25]. Disponível em: http://periodicos.

uem.br/ojs/index.php/CiencCuidSaude/article/viewFile/5656/3596

7. Gil AC. Como elaborar projetos de pesquisa. São Paulo: Atlas; 2002.

8. Minayo MCS. Pesquisa social. 27ª ed. Rio de janeiro: Vozes; 2008.

9. Duarte R. Pesquisa qualitativa: reflexões sobre o trabalho de campo [Internet].

[citado em 2009 Dez 01]. Disponível em:

http://www.scielo.br/pdf/cp/n115/a05n115.pdf

10. Bauer WM, Gaskell G. Pesquisa qualitativa com texto imagem e som. $4^{\mathrm{a}} \mathrm{ed}$.

Rio de Janeiro: Vozes; 2005.

11. Waidman MAP, Radovanovic CAT, Scardoelli MGC, Estevam MC, Pini JS,

Brischiliari A. Estratégia de cuidado a família de portadores de transtornos

mentais: experiências de um grupo de pesquisa [Internet]. [citado em 2010 Mai
16]. Disponível em:

http://periodicos.uem.br/ojs/index.php/CiencCuidSaude/article/

viewFile/9724/5537

12. Scazufca M. Abordagem familiar em esquizofrenia. Rev Bras Psiquiatr.

2000;22(2):50-3.

13. Galera SAF, Cardoso L. Doentes mentais e seu perfil de adesão ao tratamento psicofarmacológico [Internet]. [citado em 2010 Mai 09]. Disponível em: http:// www.scielo.br/pdf/reeusp/v43n1/21.pdf

14. Teixeira EH, Pereira MC, Rigacci R, Dalgalarrondo P. Esquizofrenia,

psicopatologia e crime violento: uma revisão das evidências empíricas [Internet]. [citado em 2010 Mai 15]. Disponível em: http://www.observatoriodeseguranca. org/files/esquizo-psicopatol-crimeviolento.pdf

15. Calheiros PRV, Oliveira MS, Andretta I. Comorbidades psiquiátricas no tabagismo. Rev Aletheia. 2006(23):65-74.

16. Pinho PH, Oliveira MA, Almeida MM. A reabilitação psicossocial na atenção aos transtornos associados ao consumo de álcool e outras drogas: uma estratégia possível? [Internet]. [citado em 2010 Mai 09]. Disponível em: http://www.scielo. br/pdf/rpc/v35s1/a17v35s1.pdf

17. Ministério da Saúde (BR). Saúde mental no SUS: os centros de atenção

psicossocial. Brasília: Ministério da Saúde; 2004. p. 16-28.

18. Louzã MR. Detecção precoce: é possível prevenir a esquizofrenia? [Internet]. [citado em 2010 Mai 09]. Disponível em:

http://www.scielo.br/pdf/rpc/v34s2/a04v34s2.pdf 